\title{
KELAYAKAN PENGEMBANGAN PERKEBUNAN KARET DI KABUPATEN TANAH BUMBU, KALIMANTAN SELATAN
}

\author{
Feasibility of Developing Rubber Plantation in \\ Tanah Bumbu District, South Kalimantan
}

\author{
Iif Rahmat FAUZI ${ }^{\left.1^{\star}\right)}$, Mochlisin ANDRIYANTO ${ }^{1)}$, Ernita BUKIT ${ }^{1)}$ dan ISTIANTO $^{2)}$ \\ ${ }^{1}$ Balai Penelitian Sungei Putih, Pusat Penelitian Karet \\ PO Box 1415 Medan 20001 Sumatera Utara \\ E-mail : balitsp@indosat.net.id \\ ${ }^{2}$ Balai Penelitian Getas, Pusat Penelitian Karet \\ J1. Pattimura KM 6 Salatiga Jawa Tengah
}

Diterima : 4 Agustus 2015 / Direvisi : 15 Juli 2016 / Disetujui : 26 Juli 2016

\begin{abstract}
South Kalimantan is one of the centers of rubber plantations in Indonesia. One among the areas that has the potential for plantation development is Tanah Bumbu, unfortunately with cultivation techniques traditionally managed by the people, the productivity of plantations in Tanah Bumbu is generally low. This study aimed at assessing feasibility of rubber plantation development in Tanah Bumbu. The study was conducted in 2014 with a survey method and analyzed quantitatively through the approach of environmental impact assessment (EIA) and the financial feasibility of the project investment criterias were Nett Present Value (NPV), Internal Rate of Return (IRR), Benefit Cost Ratio (B / C Ratio), and Payback Period $(P B P)$. The results showed that the development of rubber plantations in Tanah Bumbu had sufficiently potential. Financially, the location of the sample of $\pm 5.620 \mathrm{Ha}$ in the Sub-District of Hulu Kusan as land Unit I and $\pm 11.261 \mathrm{Ha}$ in the Sub-District as a unit of land Satui II showed the performance of the NPV were IDR 243.723.525.112 and IDR 187.821.589.368, $B / C$ ratio is 2.08 and 1.99, IRR is $27 \%$ and $17.53 \%$, and Payback Periode $(P B P)$ is 8 years 3 months and 13 years 9 months. Based on these criterias, the fourth rubber plantation development program in Tanah Bumbu was considered to be feasible.
\end{abstract}

Keywords: Hevea brasiliensis; Tanah Bumbu; feasibility.

\section{Abstrak}

Kalimantan Selatan merupakan salah satu sentra perkebunan karet di Indonesia, tidak terkecuali tanaman karet. Salah satu diantara tiga belas kabupaten di Provinsi Kalimantan Selatan yang memiliki potensi bagi pengembangan perkebunan karet adalah Kabupaten Tanah Bumbu. Dengan teknik budidaya yang masih tradisional, saat ini produktivitas lahan perkebunan karet di Kabupaten Tanah Bumbu umumnya masih rendah. Penelitian ini bertujuan untuk menilai kelayakan pengembangan perkebunan karet di Kabupaten Tanah Bumbu. Penelitian dilakukan pada tahun 2014 dengan metode survei dan dianalisis secara diskriptif kualitatif dan kuantitatif melalui pendekatan analisis mengenai dampak lingkungan (AMDAL) dan kelayakan finansial proyek menurut empat kriteria investasi yaitu Nett Present Value (NPV), Internal Rate of Return (IRR), Benefit Cost Ratio (B/C Ratio), dan Payback Period (PBP). Hasil analisis menunjukkan bahwa pengembangan perkebunan karet di kedua kecamatan sampel seluas $\pm 5.620 \mathrm{Ha}$ di Kecamatan Kusan Hulu sebagai Satuan Lahan I dan \pm 11.261 Ha di Kecamatan Satui sebagai Satuan Lahan II mendapatkan respon positif dari 90\% responden. Secara finansial besaran nilai dari empat kriteria investasi masing-masing adalah NPV sebesar IDR 243 Milyar dan IDR 187 Milyar, $\mathrm{B} / \mathrm{C}$ ratio sebesar 2,08 dan 1,99, selanjutnya IRR sebesar $27,20 \%$ dan $17,53 \%$, dan PBP selama 8 tahun 3 bulan dan 13 tahun 9 
bulan. Berdasarkan keempat kriteria tersebut maka program pengembangan perkebunan karet di Kabupaten Tanah Bumbu dinilai layak.

\section{Kata kunci: Hevea brasiliensis; Tanah Bumbu; kelayakan}

\section{PENDAHULUAN}

Sebagian besar wilayah Indonesia memiliki karakteristik lahan yang sesuai dengan syarat tumbuh tanaman karet. Pada umumnya areal pertanaman karet tersebar di wilayah Sumatera $(71,19 \%)$ dan Kalimantan $(24,45 \%)$. Total lahan perkebunan karet nasional tercatat mencapai 3,56 juta $\mathrm{Ha}$, dimana $85,09 \%$ diantaranya merupakan perkebunan rakyat, $6,91 \%$ perkebunan besar negara dan 7,95\% perkebunan besar swasta (Badan Pusat Statistik [BPS], 2014). Produksi karet alam nasional pada tahun 2014 mencapai angka sekitar 3,23 juta ton. Sebanyak 71,03\% diantaranya berasal dari Sumatera dan $21,59 \%$ berasal dari Kalimantan (BPS, 2014). Jumlah ini masih dapat ditingkatkan melalui kegiatan peremajaan dengan penanaman bahan tanam klon karet unggul maupun perluasan areal perkebunan dengan memberdayakan lahan-lahan kosong dan tidak produktif yang sesuai untuk perkebunan karet, terutama di Kalimantan.

Kalimantan Selatan (Kalsel) merupakan salah satu sentra produksi karet alam terbesar di Indonesia. Luas wilayah Kalsel mencapai $37.530,52 \mathrm{Km}^{2}$ atau setara dengan 3.753.052 Ha. Dari total luas tersebut $186.077 \mathrm{Ha}$ merupakan area perkebunan karet. Pada tahun 2013 tercatat bahwa dengan luas area tersebut Kalsel mampu menghasilkan produksi karet sebesar $172.372 \mathrm{~kg}$ karet kering (KK). Dengan kata lain produktivitas area perkebunan karet di Kalsel mencapai 926,35 kg KK/Ha. Tanah Bumbu adalah salah satu dari tiga belas kabupaten di Kalsel yang dinilai memiliki potensi bagi pengembangan perkebunan karet. Luas wilayah Kabupaten Tanah Bumbu sebesar 5.067,14 $\mathrm{Km}^{2}$ atau setara dengan 506.714 Ha. Sebagian besar wilayahnya masih merupakan hutan yaitu seluas 484,118 $\mathrm{Ha}$ atau 95,54\% dari total luas wilayahnya (BPS Kabupaten Tanah
Bumbu, 2015a). Dari total luas area Kabupaten Tanah Bumbu, hanya 19,55\% (99.111 Ha) dimanfaatkan untuk kegiatan pertanian baik sawah, ladang, maupun perkebunan. Selain kelapa sawit, karet merupakan komoditi primadona bagi masyarakat Kabupaten Tanah Bumbu. Total produksi karet selama tahun 2014 sebesar 18.784 ton karet mentah (BPS Kabupaten Tanah Bumbu, 2015b). Melalui kegiatan peremajaan dan perluasan perkebunan karet, Kabupaten Tanah Bumbu diperkirakan mampu meningkatkan produksi karet miliknya dan memberikan kontribusi yang berarti bagi produksi karet nasional.

Pertumbuhan dan perkembangan tanaman karet sangat dipengaruhi oleh faktor-faktor tanah, iklim, jenis tanaman (klon), dan faktor pengelolaan yang semuanya saling berkaitan erat satu dengan yang lain. Pengembangannya di suatu daerah selain didasari oleh potensi lahan, juga mempertimbangkan kondisi penggunaan lahan yang ada. Penelitian ini berupaya mengkaji kelayakan terhadap peluang pengembangan komoditas karet bedasarkan parameter luas areal, kondisi agroklimat, ketersediaan sumber daya manusia (SDM), infrastruktur, dan beberapa skema atau model pengembangan yang mungkin dapat diterapkan dalam konteks tersebut.

\section{BAHAN DAN METODE}

Penelitian dilakukan pada tahun 2013 - 2014 di dua lokasi kecamatan, yaitu Kecamatan Kusan Hulu dan Kecamatan Satui, Kabupaten Tanah Bumbu. Pemilihan lokasi dilakukan secara sengaja (purposive) berdasarkan pertimbangan potensi areal, mata pencaharian masyarakat setempat dan secara fisik ditentukan dengan melakukan overlay peta hasil evaluasi kesesuaian lahan yang telah dibuat oleh Balai Penelitian Sungei Putih, Pusat Penelitian Karet pada skala 1:50.000. Parameter yang diamati meliputi luas areal dan kesesuaian lahan, kinerja komoditas existing, potensi SDM, respon sosial, dan kelayakan finansial program pengembangan. Data yang dikumpulkan meliputi data primer dan data sekunder. Pencarian data primer dilakukan melalui metode survei dengan teknik 
wawancara terhadap 100 orang narasumber yang ditemui di sekitar wilayah pengembangan yaitu di Desa Teluk Kepayang, Desa Mangkalapi, DesaWonorejo dan Desa Makmur Mulia (non probability sampling) dengan masing-masing sebanyak 25 orang responden, sementara data sekunder diperoleh melalui teknik multiplikasi dokumen dan pencatatan data dari pemerintah daerah dan instansi terkait. Data diolah dengan menggunakan analisis diskriptif kualitatif dan kuantitatif. Analisis kualitatif dilakukan melalui pendekatan dampak lingkungan yang meliputi kriteria potensi areal, potensi agroklimat, potensi sosial budaya, arah kebijakan pemerintah, dan respon masyarakat. Sementara analisis kuantitatif dilakukan melalui pendekatan kelayakan finansial dengan empat kriteria investasi proyek yaitu Nett Present Value (NPV), Internal Rate of Return (IRR), Benefit Cost Ratio (B/C Ratio), dan Payback Period (PBP) (Jumingan, 2011).

\section{HASIL DAN PEMBAHASAN}

\section{Potensi Areal Kabupaten Tanah Bumbu}

Luas areal Kabupaten Tanah Bumbu secara administratif yaitu $5.067,14 \mathrm{Km}^{2}$ yang terdiri dari 10 kecamatan dengan total jumlah penduduk sebanyak 315.815 jiwa (Gambar 1). Tingkat kepadatan penduduk Kabupaten Tanah Bumbu sebesar 62,33 jiwa/ $\mathrm{Km}^{2}$ (BPS Kabupaten Tanah Bumbu, 2015a) sebagaimana tercantum pada Tabel 1. Ibukota Kabupaten Tanah Bumbu yaitu Kota Batulicin, tepatnya berada di Kelurahan Gunung Tinggi yang dahulu bernama Desa Pondok Butun. Sentra kegiatan usaha dan ekonomi berada di Kecamatan Simpang Empat. Sebelumnya merupakan bagian dari Kecamatan Batulicin hingga kemudian dimekarkan menjadi Kecamatan Simpang Empat.

Sebagian besar wilayah Kabupaten Tanah Bumbu masih merupakan areal hijauan baik berupa hutan, perkebunan, kebun campuran, padang, sawah, maupun pertanian tanah kering. Sebanyak 42.380 Ha $(8,36 \%)$ luas arealnya merupakan areal perkebunan yang didominasi perkebunan rakyat (Tabel 2). Diantara sejumlah kategori areal tersebut, areal yang termasuk dalam kategori hutan, padang (semak, alang, rumput), dan tanah terbuka merupakan areal yang potensial bagi perluasan perkebunan karet.
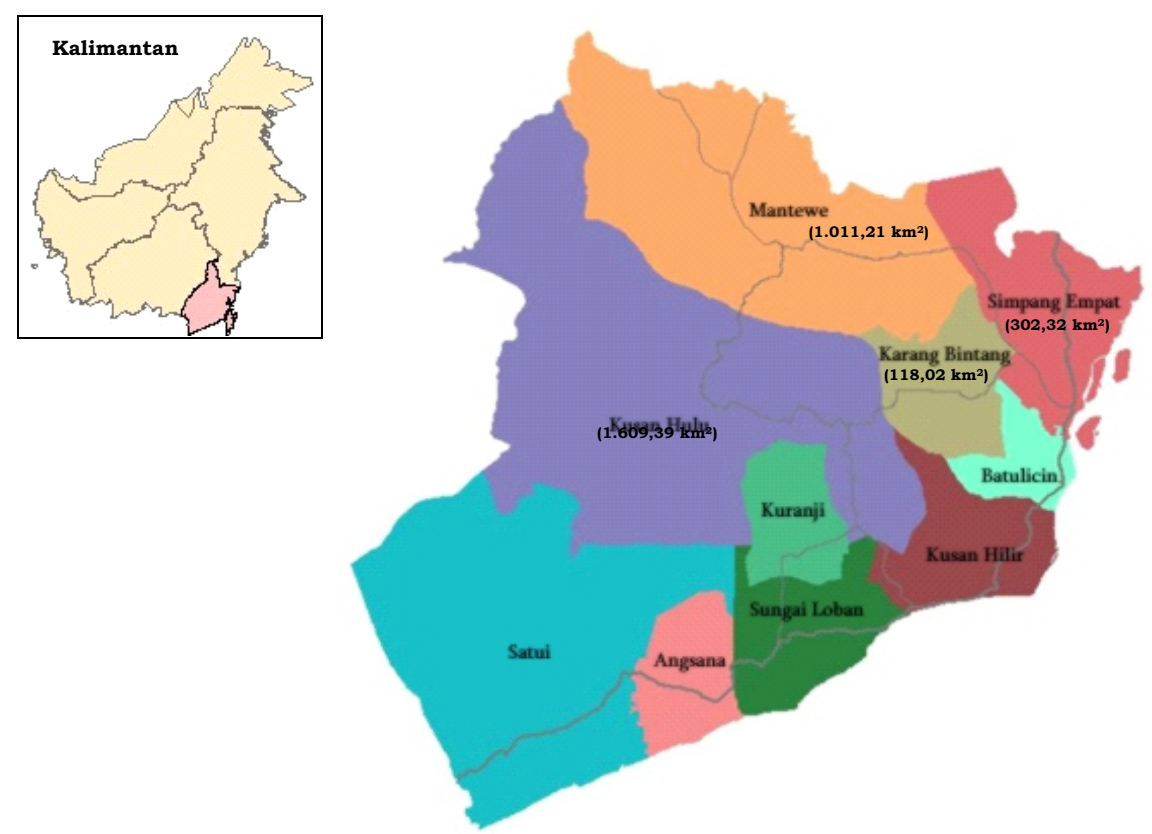

Gambar 1. Peta administratif kecamatan di Kabupaten Tanah Bumbu

Figure 1. District administrative map in Tanah Bumbu District 
Tabel 1. Luas wilayah dan kepadatan penduduk per kecamatan di Kabupaten Tanah Bumbu Table 1. The total area and population density of Tanah Bumbu District by Sub-Districs

\begin{tabular}{clccc}
\hline No. & $\begin{array}{c}\text { Kecamatan } \\
\text { Sub-District }\end{array}$ & $\begin{array}{c}\text { Luas wilayah } \\
\text { Area } \\
\left(\mathrm{Km}^{2}\right)\end{array}$ & $\begin{array}{c}\text { Jumlah penduduk } \\
\text { (Jiwa) } \\
\text { Population } \\
(\text { Person })\end{array}$ & $\begin{array}{c}\text { Kepadatan } \\
\left(\text { Jiwa/Km }{ }^{2}\right) \\
\text { Population } \\
\text { density } \\
\left(\text { Person } / \mathrm{Km}^{2}\right)\end{array}$ \\
\hline 1 & Kusan Hilir & 401,54 & 49.349 & 122,90 \\
2 & Sungai Loban & 358,41 & 21.999 & 61,38 \\
3 & Satui & 876,58 & 59.081 & 67,40 \\
4 & Angsana & 151,54 & 19.097 & 126,02 \\
5 & Kusan Hulu & $1.609,39$ & 20.547 & 12,77 \\
6 & Kuranji & 110,24 & 10.198 & 92,51 \\
7 & Batulicin & 127,71 & 16.374 & 128,21 \\
8 & Karang Bintang & 118,02 & 18.594 & 157,55 \\
9 & Simpang Empat & 302,32 & 80.830 & 267,37 \\
10 & Mantewe & $1.011,21$ & 19.746 & 19,53 \\
\hline \multicolumn{7}{c}{ Total } & $5.067,14$ & 315.815 & 62,33 \\
\hline
\end{tabular}

Sumber (Source): BPS Kabupaten Tanah Bumbu, 2015a

Tabel 2. Luas areal menurut penggunaannya di Kabupaten Tanah Bumbu, tahun 2014 Table 2. The area by land utilization in Tanah Bumbu District, year 2014

\begin{tabular}{clrr}
\hline No & \multicolumn{1}{c}{$\begin{array}{c}\text { Penggunaan lahan } \\
\text { Land use }\end{array}$} & $\begin{array}{r}\text { Luas } \\
\text { Area } \\
\text { (Ha) }\end{array}$ & $\begin{array}{r}\text { Persentase } \\
\text { Percentage } \\
(\%)\end{array}$ \\
\hline 1 & Kampung (Traditional Village) & 7.831 & 1,54 \\
2 & Industri (Industry) & 820 & 0,16 \\
3 & Pertambangan (Mining) & 1.600 & 0,32 \\
4 & Sawah (Wet Land Paddies) & 14.600 & 2,88 \\
5 & Pertanian Tanah Kering (Dry Land Paddies) & 1.810 & 0,36 \\
6 & Kebun Campuran (Mix Plantation) & 40.321 & 7,95 \\
7 & Perkebunan (Plantation) & 42.380 & 8,36 \\
8 & Padang (Semak, Alang, Rumput) (Field) (Shrub, reed,grass) & 65.439 & 12,91 \\
9 & Hutan (Forest) (Fish Pond) & 319.470 & 63,01 \\
10 & Perairan Darat (Fish & 932 & 0,18 \\
11 & Tanah Terbuka (Open Land) & 98 & 0,02 \\
12 & Lain-Lain (Etc) & 11.700 & 2,31 \\
& & 507.001 & 100 \\
\hline
\end{tabular}

Sumber (Source): BPS Kabupaten Tanah Bumbu, 2015a

Kabupaten Tanah Bumbu dikenal sebagai salah satu sentra produksi tanaman perkebunan, terutama perkebunan rakyat. Dari sepuluh kecamatan yang ada, produksi tanaman perkebunan terkonsentrasi di Kecamatan Satui dan Kecamatan Kusan Hulu. Tercatat ada 14 jenis komoditi perkebunan yang banyak dikembangkan di Kabupaten Tanah Bumbu. Diantara keempat belas komoditi tersebut, karet memiliki luas tanam tertinggi kedua setelah kelapa sawit, yaitu sebesar 25.273 Ha. Luas tanam komoditi perkebunan secara lengkap disajikan pada Tabel 3.
Selama periode 2011-2014 Kabupaten Tanah Bumbu memperoleh pendapatan kedua terbesar dari sektor pertanian dengan kontribusi mencapai 15,80\% dari total Produk Domestik Regional Bruto (PDRB) kabupaten. Kontribusi PDRB terbesar berasal dari sektor pertambangan dan penggalian (46,10\%). Tahun 2012 pertumbuhan konsumsi rumah tangga melambat $4,86 \%$ dan semakin melambat menjadi $4,17 \%$ pada tahun 2014 disebabkan kontribusi dari sektor pertambangan mengalami perlambatan (BPS Kabupaten Tanah Bumbu, 2015c). Kontribusi sektor 
Tabel 3. Luas tanaman perkebunan rakyat menurut komoditi di Kabupaten Tanah Bumbu, tahun 2014

Table 3. Planted area of smallholder by commodity in Tanah Bumbu District, year 2014

\begin{tabular}{|c|c|c|c|c|c|}
\hline \multirow{2}{*}{ No } & \multirow{2}{*}{$\begin{array}{l}\text { Tanaman } \\
\text { perkebunan } \\
\text { Estate crops }\end{array}$} & \multicolumn{4}{|c|}{$\begin{array}{l}\text { Luas } \\
\text { Area } \\
\text { (Ha) }\end{array}$} \\
\hline & & $\begin{array}{c}\text { TBM } \\
\text { Immature }\end{array}$ & $\begin{array}{l}\text { TM } \\
\text { Mature }\end{array}$ & $\begin{array}{c}\text { Tua/Rusak } \\
\text { Damaged }\end{array}$ & $\begin{array}{l}\text { Jumlah } \\
\text { Total }\end{array}$ \\
\hline 1 & Karet (Rubber) & 6.585 & 18.638 & 50 & 25.273 \\
\hline 2 & $\begin{array}{l}\text { Kelapa Sawit } \\
\text { (Palm Oil) }\end{array}$ & 13.790 & 57.579 & 10 & 71.379 \\
\hline 3 & $\begin{array}{l}\text { Kelapa Hibrida } \\
\text { (Coco Hybrida) }\end{array}$ & - & 100 & - & 100 \\
\hline 4 & $\begin{array}{l}\text { Kelapa Dalam } \\
\text { (Coconut) }\end{array}$ & 408 & 2.797 & 90 & 3.295 \\
\hline 5 & Kopi (Coffee) & 99 & 113 & - & 212 \\
\hline 6 & Kakao (Cocoa) & 27 & 38 & 15 & 80 \\
\hline 7 & Lada (Pepper) & 23 & 22 & 1 & 46 \\
\hline 8 & Cengkeh (Colve) & - & 4 & 2 & 6 \\
\hline 9 & Kemiri (Candlenut) & 11 & 7 & - & 18 \\
\hline 10 & Sagu (Sago) & 32 & 42 & 3 & 77 \\
\hline 11 & Aren (Aren) & 6 & 23 & - & 29 \\
\hline 12 & Fanili (Vanili) & - & - & - & - \\
\hline 13 & $\begin{array}{l}\text { Tebu } \\
\text { (Sugar Cane) }\end{array}$ & - & - & - & - \\
\hline 14 & Pinang (Betel) & 11 & 10 & - & 21 \\
\hline
\end{tabular}

Sumber (Source) : BPS Kabupaten Tanah Bumbu, 2015a

pertambangan dan penggalian mengalami penurunan dari 50,89\% tahun 2012 menjadi $46,06 \%$ pada tahun 2014. Kondisi ini diyakini akan terus terjadi seiring berkurangnya potensi tambang dan galian yang merupakan sumber energi tidak terbarukan. Distribusi PDRB menurut lapangan usaha disajikan pada Tabel 4.

\section{Potensi Agroklimat Tanaman Karet}

Potensi suatu lahan untuk pengembangan komoditas tertentu termasuk karet sangat dipengaruhi oleh kondisi tanah dan iklim (Susetyo \& Hadi, 2012). Apabila kedua faktor tersebut mendukung maka tanaman akan mampu menghasilkan produktivitas yang baik. Unsur iklim, tanah dan tanaman harus dikaji secara komprehensif. Kedua unsur tersebut akan sangat menentukan kualitas suatu lahan untuk jenis tanaman yang akan diusahakan. Pewilayahan agroklimat merupakan hal yang penting diketahui untuk mengantisipasi kendala iklim pembangunan kebun (Wijaya, 1995).
Kondisi tanah di Kalimantan secara umum didominasi oleh jenis tanah Ultisol (Podsolik Merah-Kuning). Ciri utama jenis tanah ini adalah kandungan haranya yang sangat rendah terutama $\mathrm{N}, \mathrm{P}, \mathrm{K}, \mathrm{Mg} ; \mathrm{pH}$ rendah dan kejenuhan Al tinggi, serta mempunyai tingkat pertukaran basa yang rendah (Wibawa \& Thomas, 1997; Prasetyo \& Suriadikarta, 2006). Kondisi agroklimat di Kabupaten Tanah Bumbu tergolong cukup sesuai (S2) untuk tanaman karet (Tabel 5), sedangkan kondisi tanahnya tergolong cukup sesuai (S2) terutama pada bagian selatan Kabupaten Tanah Bumbu, dan tergolong sesuai marginal (S3) pada areal yang termasuk ke dalam satuan lahan bagian utara (Tabel 6). Setelah dilakukan pemadanan semua parameter tanah dan iklim dengan persyaratan tumbuh tanaman karet, maka kesesuaian lahan di areal Kabupaten Tanah Bumbu dapat dilihat pada Tabel 7.

Areal yang termasuk ke dalam satuan lahan bagian selatan tergolong cukup sesuai (S2) dengan faktor pembatas 
Tabel 4. Distribusi PDRB Kabupaten Tanah Bumbu atas dasar harga berlaku menurut lapangan usaha, tahun 2012-2014

Table 4. GRDP by industrial origin at current market prices in Tanah Bumbu District, year $2012-2014$

\begin{tabular}{lccc}
\hline \multicolumn{1}{c}{$\begin{array}{c}\text { Lapangan usaha } \\
\text { Industrial origin }\end{array}$} & \multicolumn{3}{c}{$\begin{array}{c}\text { Produk Domestik Regional Bruto } \\
\text { Gross Regional Domestic Product } \\
\text { (\%) }\end{array}$} \\
\cline { 2 - 4 } & 2012 & 2013 & 2014 \\
\hline $\begin{array}{l}\text { Pertanian (Agriculture) } \\
\text { Pertambangan dan Penggalian (Mining }\end{array}$ & 14,93 & 15,62 & 15,81 \\
$\begin{array}{l}\text { and Quarrying) } \\
\text { Industri Pengolahan (Manufacturing }\end{array}$ & 50,89 & 48,27 & 46,06 \\
$\begin{array}{l}\text { Industries) } \\
\text { Listrik dan Air Bersih (Electricity and }\end{array}$ & 6,03 & 6,44 & 6,89 \\
$\begin{array}{l}\text { Water Supply) } \\
\text { Bangunan (Construction) }\end{array}$ & 0,10 & 0,11 & 0,11 \\
$\begin{array}{l}\text { Perdagangan, Hotel, dan Restoran } \\
\text { (Trade, Hotel and Restaurant) }\end{array}$ & 5,11 & 5,40 & 5,54 \\
$\begin{array}{l}\text { Pengangkutan dan Komunikasi } \\
\text { (Accomodation and Communication) }\end{array}$ & 5,28 & 5,46 & 6,03 \\
$\begin{array}{l}\text { Keuangan, Persewaan, dan Jasa } \\
\text { Perusahaan (Finance, Rent, Service of }\end{array}$ & 4,74 & 4,98 & 5,24 \\
$\begin{array}{l}\text { Company) } \\
\text { Jasa-jasa } \\
\text { (Services) }\end{array}$ & 1,39 & 1,53 & 1,59 \\
\hline \multicolumn{1}{c}{ Total } & 0,59 & 0,59 & 0,63 \\
\hline
\end{tabular}

Sumber (Source) : BPS Kabupaten Tanah Bumbu, 2015c

Tabel 5. Kelas kesesuaian agroklimat di kedua satuan lahan

Table 5. Class of agroclimate feasibility in two unit lands

\begin{tabular}{lccccc}
\hline \multirow{2}{*}{$\begin{array}{c}\text { Karakteristik iklim } \\
\text { Climate characteristic }\end{array}$} & \multicolumn{3}{c}{$\begin{array}{c}\text { Pembatas } \\
\text { Barrier }\end{array}$} & \multicolumn{2}{c}{ Kesesuaian iklim } \\
& Reasibility of climate \\
\cline { 2 - 6 } & Minimum & $\begin{array}{c}\text { Sedang } \\
\text { Medium }\end{array}$ & $\begin{array}{c}\text { Berat } \\
\text { Maximum }\end{array}$ & $\begin{array}{c}\text { Utara } \\
\text { North }\end{array}$ & $\begin{array}{c}\text { Selatan } \\
\text { South }\end{array}$ \\
\hline Ketinggian tempat (mdpl) & $0-200$ & $200-400$ & $>400$ & $0-200(\mathrm{R})$ & $0-200$ (R) \\
& $1500-3000$ & $1500-$ & $<1500$, & & \\
Curah Hujan (mm/th) & BK $<3$ & 3000 & $>3000$ & 2907 (R) & 2907 (R) \\
& $80-110$ & $115-150$ & BK $>4$ & & \\
Hari Hujan (hari/tahun) & $<15$ & $15-30$ & $>150$ & 129 (S) & 129 (S) \\
Hujan pagi (hari) & $70-80$ & $80-90$ & $>90$ & 82.40 (S) & $82.40(\mathrm{R})$ \\
Kelembaban (\%) & $<17.2$ & $17.2-24.5$ & $>24.5$ & $<17.2(\mathrm{R})$ & $<17.2(\mathrm{R})$ \\
Kecepatan angin (m/dt) & & & & Cukup & Cukup \\
Kelas kesesuaian & & & & Sesuai & Sesuai \\
\hline
\end{tabular}


Tabel 6. Kelas kesesuaian tanah di kedua satuan lahan

Table 6. Class of soil feasibility in two unit lands

\begin{tabular}{|c|c|c|c|c|c|}
\hline \multirow{2}{*}{$\begin{array}{l}\text { Karakteristik tanah } \\
\text { Soil characteristic }\end{array}$} & \multicolumn{3}{|c|}{$\begin{array}{c}\text { Pembatas } \\
\text { Barrier }\end{array}$} & \multicolumn{2}{|c|}{$\begin{array}{l}\text { Kesesuaian tanah } \\
\text { Soil feasibility }\end{array}$} \\
\hline & $\begin{array}{l}\text { Ringan } \\
\text { Minimum }\end{array}$ & $\begin{array}{l}\text { Sedang } \\
\text { Medium }\end{array}$ & $\begin{array}{c}\text { Berat } \\
\text { Maximum }\end{array}$ & $\begin{array}{l}\text { Utara } \\
\text { North }\end{array}$ & $\begin{array}{l}\text { Selatan } \\
\text { South }\end{array}$ \\
\hline Topografi (\%) & $0-16$ & $17-40$ & $>40$ & $>40(\mathrm{~B})$ & $5-40(\mathrm{~S})$ \\
\hline Kedalaman efektif (cm) & $>100$ & $45-100$ & $<45$ & 45-100 (S) & $45-100(\mathrm{~S})$ \\
\hline Batuan dipermukaan (\% & $0-15$ & $15-40$ & $>40$ & $10(\mathrm{R})$ & $10(\mathrm{R})$ \\
\hline Drainase tanah & Sedang & $\begin{array}{l}\text { Cepat, } \\
\text { Lambat }\end{array}$ & $\begin{array}{c}\text { Terhambat, sgt } \\
\text { cepat }\end{array}$ & Sedang (R) & Sedang (R) \\
\hline Tekstur tanah* & $\begin{array}{l}\text { CL,SCL, } \\
\text { SiCL,L }\end{array}$ & $\begin{array}{c}\text { CL, SiL, } \\
\text { C (50-70\%) }\end{array}$ & $\begin{array}{c}\text { C (>70\%), } \\
\text { S-SL, Si-SiL }\end{array}$ & $\mathrm{SCL}(\mathrm{R})$ & SCL (R) \\
\hline $\mathrm{pH}$ tanah & $4.0-5.5$ & $5.6-6.5$ & $<4,>5.5$ & $4.0-5.5(\mathrm{R})$ & 4.0-5.5 (R) \\
\hline Kelas kesesuaian & & & & $\begin{array}{l}\text { Cukup } \\
\text { Sesuai }\end{array}$ & $\begin{array}{l}\text { Cukup } \\
\text { Sesuai }\end{array}$ \\
\hline
\end{tabular}

Tabel 7. Kombinasi kesesuaian agroklimat

Table 7. Combination of agroclimate feasibility

\begin{tabular}{|c|c|c|c|c|}
\hline \multirow{2}{*}{$\begin{array}{l}\text { Karakteristik iklim } \\
\text { Climate characteristic }\end{array}$} & \multicolumn{4}{|c|}{$\begin{array}{c}\text { Karakteristik tanah } \\
\text { Soil characteristic }\end{array}$} \\
\hline & $\begin{array}{l}\text { Sesuai } \\
\text { Maximum }\end{array}$ & $\begin{array}{l}\text { Cukup } \\
\text { sesuai } \\
\text { Medium }\end{array}$ & $\begin{array}{c}\text { Sesuai } \\
\text { marginal } \\
\text { Minimum }\end{array}$ & $\begin{array}{l}\text { Tidak sesuai } \\
\text { Not feasible }\end{array}$ \\
\hline Sesuai & S1 & S1 & $\mathrm{S} 2$ & S3 \\
\hline Cukup Sesuai & $\mathrm{S} 2$ & $\mathrm{~S} 2$ & $\mathrm{~S} 2$ & S3 \\
\hline Sesuai Marginal & S3 & S3 & S3 & $\mathrm{N}$ \\
\hline Tidak Sesuai & $\mathrm{N}$ & $\mathrm{N}$ & $\mathrm{N}$ & $\mathrm{N}$ \\
\hline
\end{tabular}

sedang pada karakteristik agroklimat yaitu jumlah hari hujan sebanyak 197 hari/tahun dan curah hujan $2.864 \mathrm{~mm} /$ tahun, sedangkan pada karakteristik tanah juga terdapat dua faktor pembatas sedang yaitu topografi dengan kelerengan $5-40 \%$ dan kedalaman efektif tanah yang kurang dari $120 \mathrm{~cm}$. Areal yang terletak di bagian utara tergolong Sesuai Marginal (S3), pada karakteristik agroklimat terdapat dua faktor pembatas sedang yaitu jumlah hari hujan sebanyak 197 hari/tahun dan curah hujan $2.864 \mathrm{~mm} /$ tahun, sedangkan pada karakteristik tanah terdapat satu pembatas sedang yaitu kedalaman efektif tanah yang kurang dari $120 \mathrm{~cm}$ serta satu faktor pembatas berat yaitu topografi yang berbukit dengan kelerengan $>40 \%$.

Areal yang termasuk ke dalam satuan lahan bagian selatan tergolong cukup sesuai (S2) dengan faktor pembatas sedang pada karakteristik agroklimat yaitu jumlah hari hujan sebanyak 197 hari/tahun dan curah hujan $2.864 \mathrm{~mm} /$ tahun, sedangkan pada karakteristik tanah juga terdapat dua faktor pembatas sedang yaitu topografi dengan kelerengan $5-40 \%$ dan kedalaman efektif tanah yang kurang dari $120 \mathrm{~cm}$. Areal yang terletak di bagian utara tergolong Sesuai Marginal (S3), pada karakteristik agroklimat terdapat dua faktor pembatas sedang yaitu jumlah hari hujan sebanyak 197 hari/tahun dan curah hujan $2.864 \mathrm{~mm} /$ tahun, sedangkan pada karakteristik tanah terdapat satu pembatas sedang yaitu kedalaman efektif tanah yang kurang dari $120 \mathrm{~cm}$ serta satu faktor pembatas berat yaitu topografi yang berbukit dengan kelerengan $>40 \%$. 


\section{Potensi Sosial dan Budaya}

Tanah Bumbu dalam angka tahun 2015 mencatat bahwa jumlah penduduk Kabupaten Tanah Bumbu berusia 15 tahun ke atas yang bekerja di sektor pertanian dan perkebunan tercatat sebanyak 40.840 jiwa atau $43 \%$ dari total jumlah penduduk tersebut (94.802 jiwa). Disusul sektor manufaktur sebanyak 18.777 jiwa (20\%) dan sektor jasa pelayanan sebanyak 35.185 jiwa $(37 \%)$. Artinya bahwa sektor pertanian dan perkebunan masih menjadi sumber penghidupan utama bagi masyarakat Kabupaten Tanah Bumbu dan hal tersebut sekaligus merupakan potensi penting dalam upaya pengembangan perkebunan karet.

Desa Makmur Mulia sebagai salah satu lokasi di lingkup area pengembangan memiliki jumlah penduduk sebanyak 2.319 jiwa dengan jumlah penduduk laki-laki sebanyak 1.249 jiwa dan perempuan 1.070 jiwa dengan tingkat kepadatan penduduk mencapai 20 jiwa $/ \mathrm{Km}^{2}$. Terdapat $60,33 \%$ penduduk usia kerja (15 - 64 tahun), namun hanya $20,13 \%$ yang tergolong bekerja penuh, sedangkan sisanya yaitu 40,20\% bekerja secara tidak penuh. Sebanyak $64,19 \%$ kepala keluarga bermata pencaharian sebagai petani. Kondisi tersebut selain merupakan tantangan bagi Kabupaten Tanah Bumbu juga merupakan potensi yang perlu ditindak lanjuti.

Tanaman karet di Tanah Bumbu merupakan komoditas yang cukup dominan dibudidayakan oleh masyarakat setempat.
Hal ini dapat diketahui dari luas areal pertanaman karet rakyat yang mencapai $22.545 \mathrm{Ha}$ dan perkebunan besar negara seluas 2.678 Ha (BPS Kabupaten Tanah Bumbu, 2015a). Potensi tanaman karet di wilayah ini potensial untuk dikembangkan. Hasil penanaman karet di Kabupaten Tanah Bumbu menunjukkan kemampuan tumbuh tanaman yang relatif baik sebagaimana dijumpai pada tanaman umur \pm 3 tahun di sekitar areal pengembangan (Gambar 2).

Dalam kaitannya dengan kultur budidaya petani di wilayah pengembangan diketahui bahwa teknik budidaya tanaman karet yang dilakukan secara umum masih tergolong sederhana. Penanaman karet dilakukan melalui tanam langsung dengan biji. Keterbatasan tenaga kerja terampil dimungkinkan akan menjadi kendala awal dalam pengembangan perkebunan karet sehingga dibutuhkan waktu dalam melatih kemampuan teknis petani. Dengan peran kelembagaan yang ada baik pemerintah maupun perusahaan perkebunan karet di wilayah sekitar pengembangan, peningkatan kemampuan teknis petani terhadap teknologi budidaya karet yang baik akan lebih mudah diupayakan.

\section{Arah Kebijakan Pemerintah Kabupaten Tanah Bumbu}

Tanah Bumbu merupakan salah satu dari tiga belas Kabupaten di Kalimantan Selatan yang menjadi sentra produksi karet alam di Indonesia. Sekitar 8\% wilayahnya merupakan areal perkebunan
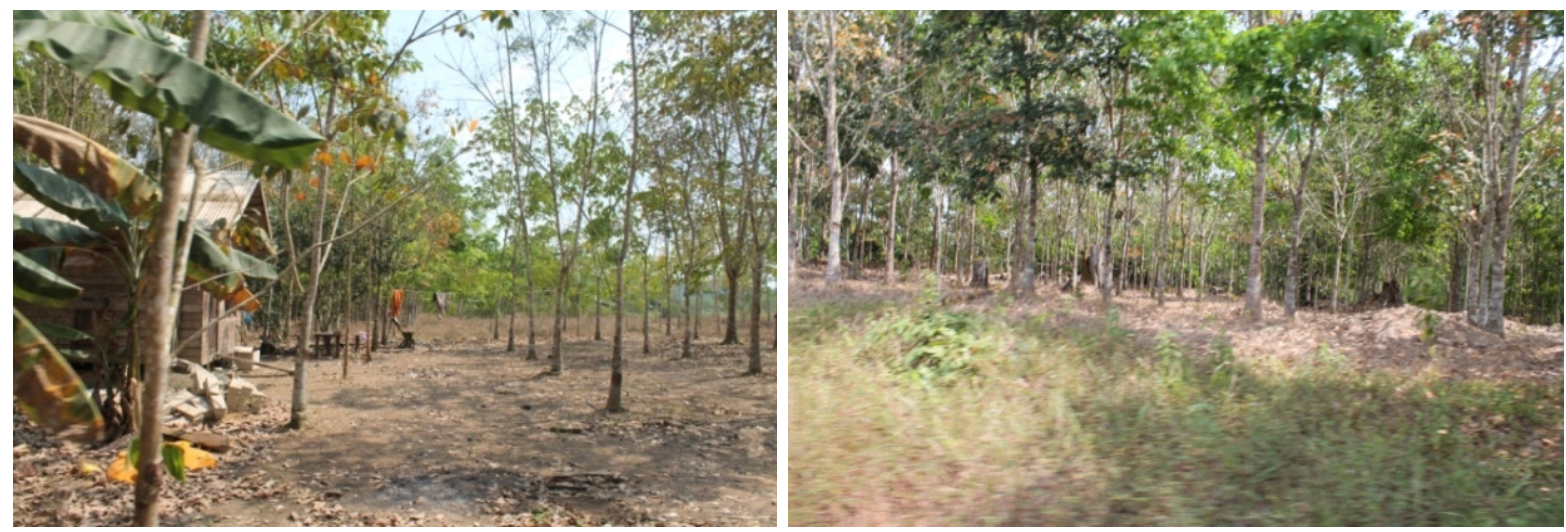

Gambar 2. Keragaan tanaman karet petani di wilayah pengembangan

Figure 2. Smallholder rubber trees at development area 
yang dikelola baik oleh negara, swasta, maupun masyarakat. Sementara hampir 80\% lainnya masih merupakan areal hijauan yang belum digali potensinya dengan optimal. Konstribusi sektor perkebunan terutama kelapa sawit dan karet menempati urutan kedua setelah sektor tambang dan galian terhadap PDRB Kabupaten Tanah Bumbu dan disadari akan menjadi sumber pendapatan utama setelah cadangan tambang dan galian habis.

Kondisi demikian disadari oleh Kabupaten Tanah Bumbu sehingga dalam beberapa tahun terakhir merencanakan pembangunan 500 Ha kebun karet dan satu unit pabrik pengolahan karet remah (crumb rubber) yang diperuntukkan bagi petani. Pada prinsipnya Kabupaten Tanah Bumbu sangat mendorong upaya peningkatan pendapatan masyarakat melalui pengembangan sektor perkebunan di wilayahnya dan sangat mengharapkan dukungan pengetahuan dan pendampingan dari lembaga pusat penelitian perkebunan sebagai centre of knowledge budidaya tanaman perkebunan yang dianggap familiar dan dipercaya oleh kalangan masyarakat perkebunan (Balai Penelitian Sungei Putih [Balit SP], 2014).

\section{Respon Masyarakat terhadap Pengembangan Perkebunan Karet}

Respon masyarakat secara umum terhadap pembangunan kebun karet di Kabupaten Tanah Bumbu pada dasarnya cukup baik. Masyarakat menyambut baik adanya rencana pembangunan perkebunan karet di wilayah desa atau kecamatan di mana mereka berada. Jika dilihat dari segi kultur mata pencaharian penduduk setempat, karet merupakan tanaman yang sangat familiar. Bahkan sebagian masyarakat meyakini bahwa tanaman karet merupakan sumber pendapatan potensial, selain hasil hutan (kayu), ladang pertanian (huma), tambang batu bara, dan pendulangan emas.

Berdasarkan data hasil wawancara dari seratus orang penduduk di desa sekitar areal pengembangan, mayoritas penduduk $(90 \%)$ memberikan persepsi positif dengan menganggap bahwa pembangunan perkebunan karet akan mampu memberikan kesempatan kerja dan berusaha. Dengan terciptanya kesempatan kerja dan berusaha serta multiplier effect lain diharapkan pendapatan penduduk setempat juga akan meningkat. Mayoritas masyarakat menyatakan pengembangan karet sesuai dengan keinginan masyarakat dimana karet diyakini memang merupakan tanaman primadona yang mampu mendukung kelangsungan hidup mereka.

Adapun sikap responden terhadap rencana pengembangan proyek perkebunan karet juga memperlihatkan hasil yang positif. Masyarakat pada umumnya memberikan dukungan terhadap seluruh tahap-tahap kegiatan pengembangan perkebunan karet. Dukungan yang diberikan seiring dengan munculnya harapan yang menitikberatkan pada meningkatnya pendapatan dan tingkat kesejahteraan hidup masyarakat di wilayah sekitar pengembangan perkebunan karet melalui terbukanya akses-akses layanan pemerintah (sosial - ekonomi) terhadap peningkatan kualitas hidup masyarakat.

\section{Kelayakan Finansial Pengembangan Perkebunan Karet}

Analisis kelayakan finansial dilakukan dengan menggunakan present value $(P V)$ yang hasilnya menunjukkan kelayakan finansial selama siklus produksi tanaman (sampai umur 25 tahun untuk setiap tahap penanaman) mencakup Analisis Nett Present Value (NPV), B/C ratio, Internal Rate of Return (IRR) dan Payback Period (PBP). Baik Future Value (FV) maupun Present Value (PV) dihitung melalui meknisme eskalasi harga dan biaya tertentu berdasarkan kecenderungan kenaikan harga dan biaya rata-rata dalam sepuluh tahun terakhir. Analisis dilakukan di dua satuan lahan di Kecamatan Kusan Hulu sebagai Satuan Lahan I (5.620 Ha) dan Kecamatan Satui sebagai Satuan Lahan II (11.261 Ha) dengan pendekatan asumsi diuraikan dalam Tabel 8.

Hasil analisis menunjukkan bahwa secara finansial pengembangan perkebunan karet di kedua kecamatan lokasi sampel seluas \pm 5.620 Ha di Kecamatan Kusan Hulu sebagai Satuan Lahan I dan $\pm 11.261 \mathrm{Ha}$ di Kecamatan Satui sebagai Satuan Lahan II layak untuk dilaksanakan dengan besaran nilai dari empat kriteria investasi masing- 
Tabel 8. Asumsi penilaian kelayakan finansial program

Table 8. Asumption of financial feasibility of programme

\begin{tabular}{|c|c|c|c|}
\hline \multirow{2}{*}{$\begin{array}{l}\text { Uraian } \\
\text { Remarks }\end{array}$} & \multirow{2}{*}{$\begin{array}{l}\text { Satuan } \\
\text { Unit }\end{array}$} & \multicolumn{2}{|c|}{$\begin{array}{l}\text { Nilai } \\
\text { Value }\end{array}$} \\
\hline & & $\begin{array}{l}\text { Lahan I } \\
\text { Areal I }\end{array}$ & $\begin{array}{c}\text { Lahan II } \\
\text { Areal II }\end{array}$ \\
\hline Luas lahan & $\mathrm{Ha}$ & 5.260 & 11.261 \\
\hline Tahap pembangunan & Tahun & 3 & 8 \\
\hline Gaji pengelola setingkat menejer & IDR / bulan & 20.000 .000 & 20.000 .000 \\
\hline Gaji pengelola setingkat askep/KTU & IDR / bulan & 10.000 .000 & 10.000 .000 \\
\hline Gaji pengelola setingkat asisten & IDR / bulan & 5.000 .000 & 5.000 .000 \\
\hline Eskalasi gaji & $\%$ & 10 & 10 \\
\hline Kantor Kebun (ukuran 150 m2) & IDR / unit & 1.500 .000 .000 & 1.500 .000 .000 \\
\hline Mess & IDR / unit & 750.000 .000 & 750.000 .000 \\
\hline Gudang (ukuran 30 m2) & IDR / unit & 300.000 .000 & 300.000 .000 \\
\hline Poliklinik & IDR / unit & 250.000 .000 & 250.000 .000 \\
\hline Eskalasi biaya & $\%$ & 5 & 5 \\
\hline Umur bangunan & Tahun & 15 & 15 \\
\hline Kendaraanpengelola setingkat menejer & IDR / unit & 450.000 .000 & 450.000 .000 \\
\hline Kendaraan pengelola setingkat askep/KTU & IDR / unit & 350.000 .000 & 350.000 .000 \\
\hline Kendaraan pengelola setingkat asisten & IDR / unit & 25.000 .000 & 25.000 .000 \\
\hline Truk PS & IDR / unit & 350.000 .000 & 350.000 .000 \\
\hline Eskalasi biaya & $\%$ & 5 & 5 \\
\hline Umur kendaraan & Tahun & 5 & 5 \\
\hline Eskalasi biaya investasi TBM & $\%$ & 2 & 2 \\
\hline Harga karet FOB & $\mathrm{USD} / \mathrm{kg}$ & 2,0 & 2,0 \\
\hline Kurs IDR terhadap USD & IDR / USD & 12.500 & 12.500 \\
\hline Notering & $\%$ FOB & 85 & 85 \\
\hline Eskalasi harga & $\%$ & 1,78 & 1,78 \\
\hline Umur tanaman karet & Tahun & 20 & 20 \\
\hline Eskalasi biaya pemeliharaan TBM/TM & $\%$ & 2 & 2 \\
\hline Upah penyadap & IDR / bulan & 3.000 .000 & 3.000 .000 \\
\hline Sistem sadap & & $1 / 2 \mathrm{~S} \mathrm{~d} / 3$ & $1 / 2 \mathrm{~S} \mathrm{~d} / 3$ \\
\hline Luas ancak & Ha/ancak & 1,5 & 1,5 \\
\hline Eskalasi upah penyadap & $\%$ & 2 & 2 \\
\hline Ongkos angkut dari lapangan ke pabrik & IDR / kgKK & 300 & 300 \\
\hline Eskalasi ongkos angkut & $\%$ & 2 & 2 \\
\hline Pajak & $\%$ & 25 & 25 \\
\hline Asal modal & & Pinjaman & Sendiri \\
\hline Menejer & Orang & 1 & 2 \\
\hline Askep & Orang & 2 & 4 \\
\hline Asisten & Orang & 8 & 16 \\
\hline KTU & Orang & 1 & 2 \\
\hline Admin & Orang & 2 & 4 \\
\hline
\end{tabular}


Tabel 9. Analisis kelayakan finansial pengembangan perkebunan karet di Kabupaten Tanah Bumbu

Table 9. Financial feasibility analysis of rubber plantation developing programme in Tanah Bumbu District

\begin{tabular}{|c|c|c|c|}
\hline \multirow[b]{2}{*}{ No } & \multirow{2}{*}{$\begin{array}{l}\text { Analisis } \\
\text { Analysis }\end{array}$} & \multicolumn{2}{|c|}{$\begin{array}{c}\text { Nilai kriteria investasi } \\
\text { Value of investation criteria } \\
\end{array}$} \\
\hline & & $\begin{array}{l}\text { Satuan Lahan I } \\
\text { Areal I }\end{array}$ & $\begin{array}{l}\text { Satuan Lahan II } \\
\text { Areal II }\end{array}$ \\
\hline 1 & NPV(DF 13\%) (IDR) & 243.723 .525 .112 & 187.821 .589 .368 \\
\hline 2 & $B / C$ ratio (DF $13 \%)$ & 2,08 & 1,99 \\
\hline 3 & $\operatorname{IRR}(\%)$ & 27,20 & 17,53 \\
\hline 4 & $P B P(t h)$ & 8,25 & 13,75 \\
\hline
\end{tabular}

masing yaitu $N P V$ adalah IDR 243,72 milyar dan IDR 187,82 milyar, $B / C$ ratio adalah 2,08 dan 1,99 , IRR adalah $27 \%$ dan $17,53 \%$, dan $P B P$ selama 8 tahun 3 bulan dan 13 tahun 9 bulan.

\section{Sensitivitas Harga dan Biaya Proyek}

Analisis sensitivitas bertujuan melihat kemampuan suatu proyek untuk bertahan dalam berbagai kondisi perekonomian. Kondisi yang sesuai dengan keadaan normal seperti yang disajikan pada Tabel 10. Kondisi yang diperkirakan mengganggu kelayakan usaha perkebunan karet dalam jangka panjang adalah jika terjadi penurunan harga dan kenaikan biaya. Analisis sensitivitas harga dan biaya juga disajikan pada Tabel 10. Asumsi tersebut diperkirakan terjadi dalam empat kondisi :
1. Kondisi pesimis harga karet alam (P) turun $5 \%$, biaya (C) naik $5 \%$.

2. Kondisi pesimis harga karet alam (P) turun $10 \%$, biaya (C) naik $5 \%$.

3. Kondisi pesimis harga karet alam (P) turun $5 \%$, biaya (C) naik 10\%.

4. Kondisi pesimis harga karet alam (P) turun $10 \%$, biaya $(\mathrm{C})$ naik $10 \%$.

Berdasarkan Tabel 10 maka kemampuan proyek pembangunan perkebunan karet di dua lokasi pengembangan untuk bertahan menghadapi kemungkinan terburuk kondisi agribisnis karet masih cukup baik. Artinya bahwa pada kondisi penurunan harga karet mencapai $10 \%$ dan kenaikan biaya mencapai $10 \%$ proyek masih layak untuk dijalankan dengan besaran nilai $N P V$ masing-masing adalah IDR 169,74 milyar dan IDR 59,00 milyar, $B / C$ ratio adalah 1,69

Tabel 10. Analisis sensitivitas harga dan biaya Table 10. Analysis of cost and price sensitivity

\begin{tabular}{|c|c|c|c|c|c|c|}
\hline \multirow{3}{*}{$\begin{array}{l}\text { Parameter } \\
\text { Parametre }\end{array}$} & \multirow{3}{*}{$\begin{array}{l}\text { Satuan } \\
\text { Lahan } \\
\text { Areal }\end{array}$} & \multicolumn{5}{|c|}{$\begin{array}{l}\text { Kondisi } \\
\text { Condition }\end{array}$} \\
\hline & & \multirow{2}{*}{$\begin{array}{l}\text { Normal } \\
\text { PO\% C0\% }\end{array}$} & \multicolumn{4}{|c|}{$\begin{array}{c}\text { Pesimis } \\
\text { Pessimistic }\end{array}$} \\
\hline & & & $\begin{array}{l}-\mathrm{P} 5 \% \\
+\mathrm{C} 5 \%\end{array}$ & $\begin{array}{l}-\mathrm{P} 10 \% \\
+\mathrm{C} 5 \%\end{array}$ & $\begin{array}{l}-\mathrm{P} 5 \% \\
+\mathrm{C} 10 \%\end{array}$ & $\begin{array}{l}-\mathrm{P} 10 \% \\
+\mathrm{C} 10 \%\end{array}$ \\
\hline \multirow[t]{2}{*}{$N P V(D F$ 13\%) (IDR Milyar) } & r) I & 243,72 & 206,76 & 182,87 & 193,69 & 169,74 \\
\hline & II & 187,82 & 123,62 & 81,25 & 101,66 & 59,00 \\
\hline \multirow[t]{2}{*}{$B / C$ ratio } & I & 2,08 & 1,87 & 1,77 & 1,78 & 1,69 \\
\hline & II & 1,99 & 1,80 & 1,70 & 1,71 & 1,62 \\
\hline \multirow[t]{2}{*}{$\operatorname{IRR}(\%)$} & I & 27,20 & 25,79 & 24,89 & 25,20 & 24,26 \\
\hline & II & 17,53 & 16,11 & 15,12 & 15,59 & 14,56 \\
\hline \multirow[t]{2}{*}{$P B P(t h)$} & I & 8,25 & 8,26 & 8,32 & 8,35 & 8,43 \\
\hline & II & 13,75 & 14,08 & 14,43 & 14,28 & 14,66 \\
\hline
\end{tabular}


dan 1,62 , IRR adalah $24,26 \%$ dan $14,56 \%$, dan $P B P$ selama 8,43 tahun dan 14,66 tahun.

\section{KESIMPULAN}

Tanah Bumbu merupakan salah satu sentra tanaman perkebunan karet rakyat yang memiliki potensi untuk berkembang. Dengan potensi areal yang belum termanfaatkan secara optimal, agroklimat yang sesuai, SDM dan sosial budaya yang memadai, serta arah kebijakan pemerintah yang mendukung maka program pengembangan perkebunan karet di Kabupaten Tanah Bumbu merupakan hal yang sangat menjanjikan. Secara finansial pengembangan perkebunan karet di kedua lokasi sampel seluas $\pm 5.620 \mathrm{Ha}$ di Kecamatan Kusan Hulu sebagai Satuan Lahan I dan $\pm 11.261 \mathrm{Ha}$ di Kecamatan Satui sebagai Satuan Lahan II maka program pengembangan perkebunan karet di Kabupaten Tanah Bumbu layak untuk dilakukan.

\section{DAFTAR PUSTAKA}

Badan Pusat Statistik. (2014). Statistik Karet Indonesia 2014. Jakarta, Indonesia: BPS.

Badan Pusat Statistik. (2015a). Tanah Bumbu dalam Angka 2015.Tanah Bumbu, Indonesia: BPS Kabupaten Tanah Bumbu.

Badan Pusat Statistik. (2015b). Statistik Daerah Kabupaten Tanah Bumbu. Tanah Bumbu, Indonesia: BPS Kabupaten Tanah Bumbu.
Badan Pusat Statistik. (2015c). Produk Domestik Regional Bruto Menurut Pengeluaran Kabupaten Tanah Bumbu 2010-2014. Tanah Bumbu, Indonesia: BPS Kabupaten Tanah Bumbu.

Balai Penelitian Sungei Putih. (2014). Bupati Tanah Bumbu Siap Dukung Peremajaan Karet untuk Rakyat. diakses dari www.balitsp.com.

Jumingan. (2011). Studi Kelayakan Bisnis : Teori dan Pembuatan Proposal Kelayakan. Jakarta, Indonesia: Bumi Aksara.

Prasetyo, B. H., \& Suriadikarta, D. A. (2006). Karakteristik, potensi, dan teknologi pengelolaan tanah ultisol untuk pengembangan pertanian lahan kering di Indonesia. Jurnal Litbang Pertanian, 25(2), 39-47.

Susetyo, I., \& Hadi, H. (2012). Pemodelan produksi tanaman karet berdasarkan potensi klon, tanah, dan iklim. Jurnal Penelitian Karet, 30(1), 23-35.

Wibawa, G. \& Thomas. (1997). Study of hevea based intercropping system functioning: A. effect of different intercrop on rubber growth. Proceedings of Study of Hevea Based Intercropping System Fungtioning Seminar (25 p.). Palembang, Indonesia: Balai Penelitian Sembawa.

Wijaya, T. (1995). Karakteristik agroklimat wilayah pengembangan karet di Irian Jaya.Prosiding Lokakarya Nasional Pemuliaan Tanaman Karet 1995 (pp. 251-261). Medan, Indonesia: Pusat Penelitian Karet. 